To the Editor of the Mathematical Gazette

SIR,-At the Oxford Mathematical Conference in April 1957, and again at the Cambridge Colloquium in the summer, it was suggested that a certain amount of Numerical Analysis might usefully be introduced into school work, even if only in an informal way. If there are other teachers whose interest in this proposal is as inhibited by their ignorance of the subject as mine was, may I be permitted to draw their attention to a recent National Physical Laboratory publication, Modern Computing Methods (H.M.S.O. Code No. 48-120-16*, price 10s. 6d. net)? I came across it by chance and have nowhere seen it advertised, but it packs into 129 pages a great deal of information about matrices, the numerical solution of linear and polynomial equations ; successive differences and their uses in interpolation, integration, and the detection of errors; the solution of ordinary and partial differential equations; relaxation methods; the preparation of mathematical tables; electronic computers and the differential analyser. There is also an extensive bibliography.

Cheltenham College

Yours, etc., A. Barton

\title{
To the Editor of the Mathematical Gazette
}

Dwar SIR, - I wish to put forward the following hypothesis with the hope that through the columns of the Gazette I may get further information to help "test" it.

"If a boy is good at rugby football and at Mathematics then he is a threequarter "!

The yardstick I have taken has been school 1st XV and A-level Maths Group III or IV at Oxford or Cambridge.

The evidence I have covers five years at Fettes College, in which time seven boys got A-Level Maths and were in the Ist XV : of the seven, six were threequarters and the seventh was a wing forward (and also a bad mathematician who was lucky to get his Group IV).

The connection first occurred to me at Edinburgh University, where I noticed that the only four members of the Honours Maths class who played senior rugby were all threequarters.

If anyone wishes to send me figures from their experience I would be pleased to analyse them.

\section{Priory House, Priory Road, Stamford, Lincolnshire}

Yours etc., Bruce M. McKrenzie

To the Editor of the Mathematical Gazette

Sin,-The recent review of Professor Tarski's Logic, Semantics and Metamathematics refers to the loss which foundation studies sustained in the tragic death in a motor accident of Dr. J. Kalicki, a young colleague of Professor Tarski's. I wish to point out that Dr. Kalicki himself was the driver of the car in which the accident occurred, and not Professor Tarski, as the reviewer stated.

Princeton University

Yours, ete., Dana ScotT

\section{QUERY}

Can any reader throw light on the following definition, or suggest any polyhedra which conform to it?

Doubly reversible polyhedron. A polyhedron which exhibits, in the faces touching the base, a series repeated twice. So in a trebly reversible polyhedron, etc., the series is repeated thrice, etc.

Source : Century Dictionary, 1889.

Credit : Prof. Pierce.

H.M.C. 